DOI: 10.12957/demetra.2016.18380

\title{
A "dieta da proteína" reduz o diâmetro e a densidade volumétrica glomerular em ratas
}

\section{The "protein diet" reduces diameter and glomerular volumetric density in rats}

\author{
Vania Mattoso Ribeiro' \\ Ana Claudia Pascoal ${ }^{2}$ \\ Eduardo de Salvo Castro² \\ Maria Augusta Fantezia Moulin ${ }^{3}$ \\ Jorge Luiz Medeiros Júnior ${ }^{4}$ \\ Vilma Blondet de Azeredo ${ }^{5}$
1 Universidade Federal Fluminense, Faculdade de Farmácia, Programa de Pós-graduação em Ciências Aplicadas a Produtos para Saúde. Niterói-RJ, Brasil.
2 Universidade Federal Fluminense, Faculdade de Nutrição, Laboratório de Nutrição Experimental. Niterói-RJ, Brasil.
${ }^{3}$ Universidade Federal Fluminense, Faculdade de Nutrição. Niterói-RJ, Brasil.
${ }^{4}$ Universidade do Estado do Rio de Janeiro, Programa de Pós-graduação de Biologia Humana e Experimental. Rio de Janeiro-RJ, Brasil.
${ }^{5}$ Universidade Federal Fluminense, Departamento de Nutrição e Dietética, Faculdade de Nutrição. Niterói-RJ, Brasil. \\ Este artigo é baseado na dissertação de mestrado \\ intitulada "Efeito da dieta da proteína sobre 0 \\ metabolismo renal", do curso de pós-graduação \\ em Ciências Aplicadas a Produtos para Saúde da \\ Faculdade de Farmácia, Universidade Federal \\ Fluminense, defendida em abril de 2014. \\ Correspondência / Correspondence \\ Vânia Mattoso \\ E-mail:vaniamattoso@yahoo.com.br
}

\section{Resumo}

Objetivo: O objetivo deste estudo foi avaliar o efeito do consumo da dieta da proteína na morfologia do tecido renal. Métodos: Quarenta Rattus Norvegicus wistar albino, adultas, foram divididas em quatro grupos $(\mathrm{n}=10)$ : Controle 1 (C1), Controle 2 (C2), Hiperproteico 1 (HP1) e Hiperproteico 2 (HP2). Os grupos C2 e HP2 foram submetidos à restrição alimentar de $30 \%$. Ao final do experimento, os rins foram retirados, pesados e seu comprimento e largura, aferidos. Posteriormente, foram clivados através do método orientator, fixados em formalina e incluídos em parafina. As lâminas dos cortes histológicos foram coradas pela técnica de Hematoxilina \& Eosina e fotomicrografadas. A densidade volumétrica glomerular foi determinada por método estereológico, e o diâmetro dos glomérulos renais foi calculado com auxílio do software Image J. Análises séricas foram realizadas pelo método colorimétrico. Os resultados são expressos como média e desvio padrão. Para comparação das médias entre os grupos, foram utilizados ANOVA e Tukey como pós-teste, aceitando nível de significância de 5\%. Resultados: Os grupos hiperproteicos apresentaram maior pressão arterial. O tamanho e peso renal do grupo HP1 foram maiores do que C1 e C2. O grupo HP1 mostrou diâmetro glomerular inferior e o grupo HP2 mostrou densidade volumétrica glomerular inferior aos grupos C1 e C2. Conclusão: A "dieta da proteína" pode causar aumento da pressão arterial sistólica, morfologia renal anormal, redução do diâmetro e na densidade volumétrica glomerular. Assim, o estudo sugere que essa dieta possa levar a alterações no tecido renal, predispondo ao desenvolvimento de doenças crônicas.

Palavras-chave: Rim. Dieta. Glomérulos Renais. Proteínas na Dieta. 


\section{Abstract}

Objective: This study aimed to evaluate the effect of protein diet in kidney morfology. Methods: Forty Rattus Norvegicus Wistar albino, adults, were divided into four groups $(\mathrm{n}=10)$ : Control 1 (C1) Control 2 (C2), High Protein 1 (HP1) and High Protein 2 (HP2). C2 and HP2 groups were subjected to $30 \%$ of food restriction. At the end of the experiment, kidneys were removed, weighed and its length and width, measured. Thereafter, they were cleaved by Orientator method, fixed in formalin and embedded in paraffin. The blades of the histological sections were stained with Hematoxylin \& Eosin technique and photomicrographed. Glomerular density was determined by stereological method and the diameter of renal glomeruli was calculated using Image $\mathrm{J}$ software. Serum were performed by the colorimetric method. Results are expressed as mean and standard deviation. To compare the means between groups, it was used ANOVA and Tukey as post-test, accepting a significance level of 5\%. Results: The HP groups had higher blood pressure. The size and kidney weight of HP1 was greater than C1 and C2. The HP1 group showed lower glomerular diameter and the HP2 group showed lower glomerular density than C1 and C2 groups. Conclusion: The "protein diet" can cause increased systolic blood pressure, abnormal renal morphology, reduced glomerular diameter and glomerular volume density. This study suggests that this diet can lead to changes in kidney tissue, predisposing to development of chronic diseases.

Key words: Kidney. Diet. Kidney Glomerulus. Dietary Proteins.

\section{Introdução}

A procura pela dieta da proteína tem sido o caminho buscado por uma parcela da população para obtenção de um corpo magro em curto espaço de tempo ${ }^{1,2}$ Essa dieta se caracteriza pelo elevado teor protéico e lipídico e baixa concentração de carboidratos; $;{ }^{2,3}$ entretanto, a segurança do consumo excessivo de proteínas tem sido questionada e algumas evidências apontam que dietas com tal concentração de proteínas podem ocasionar danos no tecido renal. ${ }^{4-7}$

As alterações renais promovidas pelo alto consumo de proteínas têm sido atribuídas à maior carga de trabalho recebida pelo órgão, secundária à filtração aumentada de metabólitos protéicos, especialmente ureia e creatinina. ${ }^{8}$ Outro fator envolvido é o desenvolvimento da acidose metabólica, ocasionada pela elevada produção de corpos cetônicos, resultante do metabolismo proteico e lipídico. ${ }^{6}$ 
Tais fatores estão associados a hipertrofia renal, hiperfiltração glomerular, aumento da excreção urinária de albumina, aumento da diurese, natriurese, caliurese associada a mudanças na pressão arterial, aumento do risco para nefrolitíase, alterações na morfologia renal, fibrose intersticial e aumento na produção de espécies reativas de oxigênio, com consequente aumento do estresse oxidativo.-11 Essas consequências são respostas a uma hemodinâmica renal anormal, além de serem um antecedente ao dano renal e fator coadjuvante no desenvolvimento de doenças renais. ${ }^{11,12}$

Todavia, a literatura ainda é contraditória quanto ao efeito do consumo excessivo de proteínas e a manutenção da integridade do órgão, uma vez que alguns pesquisadores não verificaram associações da alta ingestão proteica com o dano renal. ${ }^{4,5}$

Assim, o objetivo deste estudo foi avaliar o efeito do consumo da "dieta da proteína" sobre o tecido renal, visando avaliar possíveis alterações que possam ocorrer em decorrência da adoção de uma dieta com este perfil.

\section{Materiais e Métodos}

O estudo foi realizado no Laboratório de Nutrição Experimental do Departamento de Nutrição e Dietética da Faculdade de Nutrição da Universidade Federal Fluminense, com Rattus Norvergicus Wistar albino, fêmeas, com 90 dias de vida, pesando aproximadamente $200 \mathrm{~g}$. Todos os animais foram mantidos em experimentação por 60 dias, em gaiolas individuais de polipropileno devidamente identificadas, em ambiente com temperatura constante $\left(24^{\circ} \mathrm{C} \pm 2^{\circ} \mathrm{C}\right)$ e iluminação adequada com ciclo claro e escuro de 12 em 12 horas.

Os animais foram divididos em quatro grupos (n=10/grupo): 1) Grupo Controle (C1) e 2) Grupo Controle 2 (C2)*- que receberam ração constituída de 69,20\% de carboidratos (59,20\% de amido e 10\% de açúcar); 11,30\% de proteína (caseína); 4,80\% de lipídio (óleo de soja); $1 \%$ de mistura vitamínica (Prag soluções, São Paulo, Brasil); 3,5\% de mistura de minerais (Prag Soluções, São Paulo, Brasil); $5 \%$ de fibras (celulose); 0,25\% de bitartarato de colina e 0,18\% de L-cistina, manufaturadas, seguindo as recomendações do American Institute of Nutrition (AIN-93M); 3) Grupo Hiperproteico 1 (HP1) e 4) Grupo Hiperproteico 2 (HP2)*- que receberam ração contendo 4,73\% de glicídio (lactose); 49,77\% de proteína (47,54\% de proteína da carne bovina e 2,23\% de proteína do leite); 15,97\% de lipídio (11,97\% gordura animal da carne e 4\% óleo de soja); $1 \%$ de mistura de vitaminas (Prag Soluções, São Paulo, Brasil); 3,5\% de mistura de minerais (Prag Soluções, São Paulo, Brasil); $7 \%$ de fibras ( $5 \%$ celulose e $2 \%$ Agar); 0,18\% de L-cistina e 0,25\% de bitartarato de colina.

O Agar foi usado para dar liga e moldar a ração. *Os Grupos C2 e HP2 receberam 70\% da quantidade de ração consumida pelos grupos C1 e HP1. 
Os ingredientes para a formulação da ração baseada na "dieta da proteína" foram adquiridos no comércio local. A carne bovina (acém) foi desidratada, triturada, peneirada e misturada aos outros ingredientes.

O cuidado dos animais foi realizado disponibilizando-se água em livre demanda para todos os grupos. O peso corporal ( $\mathrm{g}$ ) e o consumo de água $(\mathrm{ml})$ foram aferidos semanalmente utilizando balança (Bioprecisa JY 50001, de precisão 0,1g) e proveta, respectivamente. A sobra da água foi quantificada para obtenção da ingestão diária. O controle da oferta e sobra de ração dos grupos C1 e HP1 foi realizado semanalmente. Já dos grupos C2 e HP2, o controle foi feito diariamente em função da restrição alimentar de $30 \%$ a que foram submetidos.

A pressão arterial dos animais foi aferida, semanalmente, durante o experimento, utilizando pletismógrafo de cauda da marca Insight ${ }^{\circledR}$, sendo expressa em $\mathrm{mmHg}$.

Ao final do período experimental, todos os animais foram submetidos ao procedimento de lavado vaginal para identificação da fase do ciclo estral. Após esta análise, aqueles que estavam na fase "estro" do ciclo foram separados e mantidos em jejum por seis horas para posterior sacrifício. Foram, então, anestesiados com injeção intraperitoneal. A coleta de sangue foi realizada por punção cardíaca. O sangue foi coletado em tubos sem anticoagulante e centrifugado para obtenção do soro. As amostras de soro foram congeladas a $-80^{\circ} \mathrm{C}$ para análises posteriores.

Em seguida, todos os animais foram submetidos ao procedimento de laparotomia mediana. Os rins foram retirados, pesados (g) e seu comprimento e largura aferidos com paquímetro modelo Lee Tools (precisão $0.05 \mathrm{~mm}$ ), sendo expressos em centímetros.

Os rins foram fixados em formalina tamponada a 4\%. Posteriormente, foram clivados através do método Orientator, processados para técnica histológica de inclusão em parafina e cortados com espessura de $5 \mu \mathrm{m}$. As lâminas foram coradas pela técnica de Hematoxilina \& Eosina para realização de todas as análises histomorfométricas. A densidade volumétrica glomerular (Vv,[Glom], \%) foi determinada por método estereológico utilizando o Sistema-teste M-42, em 25 campos aleatórios por animal.

Todos os cortes de tecidos utilizados para microscopia de luz foram fotografados sob as mesmas condições e com uma resolução de 2.040x1.536 pixels, com uma câmera digital (Olympus DP70, Tóquio, Japão) diretamente acoplada ao microscópio (Olympus BX51, Tóquio, Japão).

A determinação do diâmetro glomerular foi realizada em 25 campos aleatórios por animal, com auxílio do software Image J, versão 1.47, através de duas medidas lineares, em dois eixos diferentes, de cada glomérulo. Os resultados foram expressos em $\mu \mathrm{m}$. 
Em relação aos parâmetros bioquímicos, foi determinada a concentração sérica de ureia, proteínas totais e creatinina por método colorimétrico utilizando kits comerciais (BioClin, Belo Horizonte, Brasil). A concentração sérica de aldosterona e interleucina- 6 foi determinada pelo método Enzyme Linked ImmunonoSorbent Assay (ELISA) utilizando kits comerciais (UScn, Life Science Inc).

Os resultados são apresentados através da estatística descritiva como média aritmética e desvio padrão. Foram realizadas análises comparativas entre as médias das variáveis estudadas dos quatro grupos, através da análise de variância (ANOVA one-way) e Tukey como pós-teste. Para suportar as análises propostas, foram realizados testes de Kurtosis e Skewness para verificação da normalidade dos dados. A correlação de Pearson foi usada para verificar possíveis associações entre as variáveis estudadas. Foi aceito nível de significância de $5 \%$, sendo utilizado o programa GraphPad InStat (versão 3.10, ano 2009).

Para este estudo, foram seguidos os critérios estabelecidos pelo Colégio Brasileiro de Experimentação Animal (COBEA, 2011) e Sociedade Brasileira de Ciência em Animais de Laboratório (SBCAL). O presente projeto foi submetido ao comitê de ética responsável por pesquisas em animais de laboratório da UFF, tendo sido aprovado com protocolo número 0027/08.

\section{Resultados}

Pôde-se observar, durante o experimento, que os grupos que receberam ração em livre demanda (C1 e HP1) apresentaram aumento do peso corporal, enquanto que aqueles que foram submetidos a restrição alimentar (C2 e HP2) perderam peso $(p<0,0001)$. Em se tratando da ingestão alimentar diária, os grupos C1 e HP1 apresentaram maior consumo de ração em relação aos grupos que tiveram restrição alimentar $(p<0,0002)$, segundo a tabela 1 .

O grupo que recebeu dieta hiperproteica em livre demanda (HP1) apresentou maior ingestão de água quando comparado aos outros grupos. Os demais grupos apresentaram ingestão hídrica semelhante $(p<0,0001)$ (tabela 1). Observou-se, também, que os grupos que receberam a "dieta da proteína" apresentaram diurese maior do que os grupos controle (dados observacionais não apresentados).

Na tabela 2, pode-se observar que o rim esquerdo do grupo HP1 apresentou-se mais pesado frente aos demais grupos, enquanto que o rim direito do grupo HP1 apresentou-se mais pesado apenas quando comparado ao grupo C2 ( $p<0,0001)$. Quanto ao tamanho do órgão, foi observado que os rins esquerdo e direito dos animais do grupo HP1 apresentaram maior tamanho quando comparados aos grupos C1, C2 e HP2 ( $p<0,0001)$. Quando comparados ao grupo controle, o rim direito do grupo HP1 apresentou tamanho 66\% maior frente ao grupo C1, enquanto que o rim esquerdo apresentou-se $57 \%$ maior quando comparado ao grupo controle (tabela 2). 
Tabela 1. Análise das variáveis de peso, consumo de ração e ingestão hídrica dos animais ao longo do tratamento, Rio de Janeiro-RJ, 2012.

\begin{tabular}{l|cccc|c}
\hline & C1 & HP1 & C2 & HP2 & $p$ valor \\
\hline $\begin{array}{l}\text { Peso inicial } \\
(\mathrm{g})\end{array}$ & $235,4 \pm 13,17$ & $237,2 \pm 7,28$ & $237,2 \pm 3,03$ & $234,6 \pm 17,17$ & 0,05 \\
\hline $\begin{array}{l}\text { Peso final } \\
(\mathrm{g})\end{array}$ & $277,4 \pm 15,82^{\mathrm{a}}$ & $272,8 \pm 23^{\mathrm{a}}$ & $192,8 \pm 13,33^{\mathrm{b}}$ & $194,8 \pm 3,70^{\mathrm{b}}$ & 0,03 \\
\hline $\begin{array}{l}\text { Variação de } \\
\text { peso }(\Delta)\end{array}$ & $27,33 \pm 7,09^{\mathrm{a}}$ & $30,3 \pm 15,00^{\mathrm{a}}$ & $-16,6 \pm 6,10^{\mathrm{b}}$ & $-15,80 \pm 3,03^{\mathrm{b}}$ & 0,0001 \\
\hline $\begin{array}{l}\text { Consumo de } \\
\text { ração (g/dia) }\end{array}$ & $10,96 \pm 1,38^{\mathrm{a}}$ & $10,98 \pm 0,96^{\mathrm{a}}$ & $8,35 \pm 0,18^{\mathrm{b}}$ & $8,39 \pm 0,20^{\mathrm{b}}$ & 0,0002 \\
\hline $\begin{array}{l}\text { Ingestão hídrica } \\
(\mathrm{mL} / \text { dia) }\end{array}$ & $22,97 \pm 3,99^{\mathrm{a}}$ & $37,47 \pm 4,53^{\mathrm{b}}$ & $21,65 \pm 5,25^{\mathrm{a}}$ & $26,42 \pm 2,44^{\mathrm{a}}$ & 0,0001 \\
\hline
\end{tabular}

Grupo controle 1 (C1); Grupo Hiperproteico 1 (HP1); Grupo Controle 2 (C2) Grupo hiperproteico 2 (HP2). Diferentes letras sobrescritas denotam diferença estatística entre os grupos (ANOVA uni-variada, $P<0,05$ ).

Tabela 2. Análise morfométrica dos rins dos animais após 60 dias de tratamento, Rio de Janeiro-RJ, 2012.

\begin{tabular}{|c|c|c|c|c|c|}
\hline & $\mathrm{C} 1$ & HP1 & $\mathrm{C} 2$ & HP2 & $p$ valor \\
\hline \multicolumn{6}{|l|}{ Peso dos rins } \\
\hline Esquerdo & $0,78 \pm 0,04^{\mathrm{a}}$ & $1,00 \pm 0,17^{\mathrm{b}}$ & $0,61 \pm 0,07^{\mathrm{a}}$ & $0,74 \pm 0,09^{a}$ & 0,0001 \\
\hline Direito & $0,85 \pm 0,10^{\mathrm{a}, \mathrm{b}}$ & $1,08 \pm 0,10^{\mathrm{b}}$ & $0,64 \pm 0,053^{\mathrm{a}}$ & $0,92 \pm 0,20^{\mathrm{a}, \mathrm{b}}$ & 0,0001 \\
\hline \multicolumn{6}{|l|}{$\begin{array}{l}\text { Tamanho } \\
\text { dos rins }(\mathrm{cm})\end{array}$} \\
\hline Esquerdo & $1,12 \pm 0,44^{\mathrm{a}}$ & $1,76 \pm 0,05^{\mathrm{b}}$ & $0,64 \pm 0,11^{c}$ & $0,74 \pm 0,13^{\mathrm{a}}$ & 0,0001 \\
\hline Direito & $1,080 \pm 0,37^{\mathrm{a}}$ & $1,80 \pm 0,10^{\mathrm{b}}$ & $0,64 \pm 0,05^{\mathrm{c}}$ & $0,84 \pm 0,16^{\mathrm{a}}$ & 0,0001 \\
\hline
\end{tabular}

Grupo controle 1 (C1); Grupo Hiperproteico 1 (HP1); Grupo Controle 2 (C2); Grupo Hiperprotéico 2 (HP2). Grupos submetidos a 30\% de restrição alimentar (C2 e HP2). Diferentes letras sobrescritas denotam diferença estatística entre os grupos (ANOVA uni-variada, $P<0,05$ ).

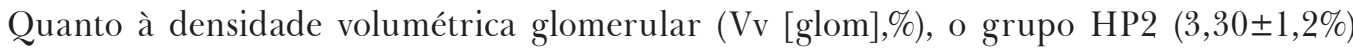
apresentou menor Vv quando comparada aos grupos C1 (5,75 $\pm 1,70 \%)$, C2 $(6,05 \pm 1,17 \%)$ e HP1 $(4,46 \pm 0,70 \%)(P<0,0001)$. 
Ao avaliar o diâmetro dos glomérulos dos rins dos animais, verificou-se que o grupo HP1 $(54,87 \pm 4,54 \mu \mathrm{m})$ apresentou menor diâmetro quando comparado aos grupos C1 (75,25 $\pm 2,35 \mu \mathrm{m})$, C2 $(69,05 \pm 3,79 \mu \mathrm{m})$ e HP2 $(68,82 \pm 3,09 \mu \mathrm{m})(p<0,001)$.

As análises bioquímicas do sangue são apresentadas na tabela 3. Observa-se que o grupo C1 apresentou maiores concentrações séricas de albumina em relação aos grupos C2, HP1 e HP2 $(p<0,007)$, enquanto que não foram observadas diferenças significativas nas concentrações séricas de creatinina entre os grupos.

Em se tratando de proteínas totais, o grupo Cl apresentou maior concentração apenas em relação ao grupo HP2 ( $p<0,01)$. Ao observar as concentrações de ureia, o grupo HP1 apresentou maior concentração em relação aos grupos C1 e C2, porém semelhante ao grupo HP2 $(p<0,0002)$ (tabela 3).

Quanto à aldosterona, o grupo que consumia “dieta da proteína” com restrição (HP2) apresentou-se maior concentração quando comparado aos demais grupos ( $\mathrm{p}<0,0001)$. No tocante à interleucina-6, os grupos controle apresentaram menores concentrações quando comparados aos grupos alimentados com dieta hiperproteica $(p<0,0002)$ (tabela 3).

Tabela 3. Análises bioquímicas dos animais após 60 dias de tratamento, Rio de Janeiro-RJ, 2012.

\begin{tabular}{l|cccc|c}
\hline & C1 & HP1 & C2 & HP2 & p valor \\
\hline $\begin{array}{l}\text { Albumina } \\
(\mathrm{g} / \mathrm{dL})\end{array}$ & $4,10 \pm 0,62^{\mathrm{a}}$ & $3,55 \pm 0,35^{\mathrm{b}}$ & $3,32 \pm 0,3^{\mathrm{b}}$ & $3,48 \pm 0,25^{\mathrm{b}}$ & 0,007 \\
\hline $\begin{array}{l}\text { Creatinina } \\
(\mathrm{mg} / \mathrm{dL})\end{array}$ & $0,46 \pm 0,05$ & $0,54 \pm 0,09$ & $0,44 \pm 0,05$ & $0,48 \pm 0,08$ & 0,7 \\
\hline $\begin{array}{l}\text { Proteínas Totais } \\
(\mathrm{mg} / \mathrm{dL})\end{array}$ & $7,12 \pm 0,79^{\mathrm{a}}$ & $6,48 \pm 0,77^{\mathrm{a}, \mathrm{b}}$ & $6,42 \pm 0,68^{\mathrm{a}, \mathrm{b}}$ & $5,74 \pm 0,73^{\mathrm{b}}$ & 0,01 \\
\hline $\begin{array}{l}\text { Interleucina-6 } \\
\text { (pg/mL) }\end{array}$ & $294,22 \pm 41,68^{\mathrm{a}}$ & $457,3 \pm 74,32^{\mathrm{b}}$ & $390,60 \pm 57,62^{\mathrm{a}, \mathrm{b}, \mathrm{d}}$ & $535,45 \pm 97,62^{\mathrm{b}, \mathrm{c}}$ & 0,0002 \\
\hline $\begin{array}{l}\text { Uréia } \\
(\mathrm{mg} / \mathrm{dL})\end{array}$ & $34,36 \pm 5,14^{\mathrm{b}}$ & $48,43 \pm 12,8^{\mathrm{a}}$ & $34,5 \pm 6,02^{\mathrm{b}}$ & $41,75 \pm 9,66^{\mathrm{a}}$ & 0,0002 \\
\hline $\begin{array}{l}\text { Aldosterona } \\
\text { (pg/mL) }\end{array}$ & $0,26 \pm 0,08^{\mathrm{a}}$ & $0,20 \pm 0,06^{\mathrm{a}}$ & $0,15 \pm 0,08^{\mathrm{a}}$ & $0,62 \pm 0,07^{\mathrm{b}}$ & 0,0001 \\
\hline
\end{tabular}

Grupo controle 1 (C1); Grupo Hiperproteico 1 (HP1); Grupo Controle 2 (C2); Grupo Hiperproteico 2 (HP2). Grupos submetidos a 30\% de restrição alimentar (C2 e HP2). Diferentes letras sobrescritas denotam diferença estatística entre os grupos (ANOVA uni-variada, $P<0,05$ ). 
Ao avaliar a pressão sistólica dos animais, os grupos C1 $(111,09 \pm 18,69)$ e C2 $(92,78 \pm 12,48$

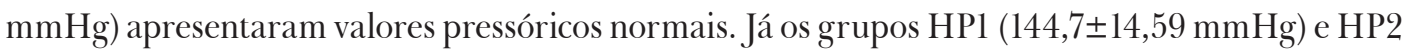
$(137,85 \pm 3,89 \mathrm{mmHg})$ apresentaram valores elevados em relação aos controles $(\mathrm{p}<0.005)$. Quanto à pressão diastólica, não houve diferença significativa entre os grupos.

\section{Discussão}

Em seu livro, Dr. Atkins ${ }^{3}$ afirma que os indivíduos que seguem sua dieta hiperproteica, embora consumam maior quantidade de energia/dia, conseguem perder peso. Entretanto, ainda não existem evidências científicas que confirmem que esta dieta tenha vantagens metabólicas frente às dietas tradicionais na perda ponderal. . $^{3,14}$

O presente estudo mostra que, quando a dieta hiperproteica é associada a uma restrição alimentar, a perda ponderal mostra-se semelhante à de uma dieta hipocalórica balanceada, evidenciando que não é a composição da dieta e, sim, a redução do consumo energético diário que leva à redução de peso.

Sabe-se que uma dieta hiperproteica leva à produção de corpos cetônicos derivados da oxidação lipídica e dos aminoácidos cetogênicos. Estes levam ao aumento da osmolalidade plasmática e, assim, desencadeiam a sensação de sede e o maior consumo hídrico. ${ }^{15}$ Tal fato foi observado neste estudo, onde os grupos que receberam dieta da proteína apresentaram maior ingestão de água frente aos grupos alimentados com dieta controle (tabela 1). Adicionalmente, a excreção das cetonas pelo rim é acompanhada da excreção de sódio, o que causa aumento da diurese, fato também observado durante o experimento (dados observacionais não apresentados). ${ }^{13,14}$

A proteína dietética tem sido reconhecida como moduladora da função renal. Alguns estudos demonstraram que o consumo proteico afeta o tamanho dos rins, tornando-os maiores, devido à maior carga de trabalho recebida pelo órgão, secundária à filtração aumentada de metabólitos proteicos, especialmente ureia. ${ }^{16,17}$ Outros estudos sugerem que a hiperfiltração em resposta à maior carga de nitrogênio e maior demanda por clearance renal é um mecanismo adaptativo normal, similar ao que ocorre em mulheres grávidas., ${ }^{4,5}$

Em se tratando da hipertrofia renal, cabem duas explicações plausíveis: a primeira hipótese, supracitada, se refere a um mecanismo compensatório para permitir a excreção de uma maior carga molar renal. Já a segunda sugere que o aumento do consumo protéico aumenta o hormônio do crescimento, provavelmente através do fator de crescimento semelhante à insulina tipo 1, (IGF-1), o que pode ser responsável pelo aumento do tamanho do órgão. Entretanto, os autores sugerem que tal hiperplasia possa ser momentânea e, uma vez cessando a oferta extra de proteínas, o órgão retorne a seu tamanho original. ${ }^{17}$ 
No presente trabalho, foi verificado que o grupo que recebeu dieta hiperproteica em livre demanda (HPl) apresentou maior peso (em gramas) e maior tamanho (em centímetros) renal frente aos grupos controle (C1 e C2) e frente ao grupo hiperproteico restrito (HP2), demonstrando que o aumento da ingestão proteica tem efeito direto nesses parâmetros morfométricos (tabela 2). Resultados semelhantes foram encontrados por Aparicio et al. ${ }^{3}$, no qual os rins de animais alimentados com dieta hiperproteica à base de proteína vegetal foram mais pesados do que aqueles alimentados com dieta controle.

No presente estudo, os animais que receberam dieta hiperproteica com restrição (HP2) apresentram menor densidade volumétrica glomerular (figura 1), possivelmente devido ao aumento da sobrecarga renal somado ao estresse proporcionado pela restrição alimentar, levando à perda de néfrons neste grupo. ${ }^{12,18}$

\section{DENSIDADE VOLUMÉTRICA GLOMERULAR (Vv)}

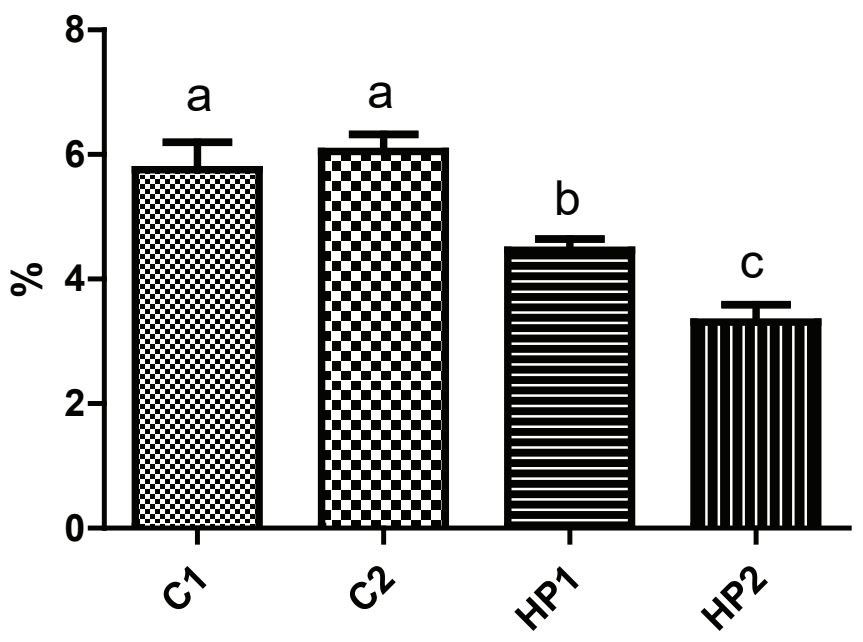

Figura 1. Densidade volumétrica glomerular. Grupo controle (C); Grupo Hiperproteico (HP). Grupos submetidos a 30\% de restrição alimentar (C2 e HP2). Diferentes letras sobrescritas denotam diferença estatística entre os grupos (ANOVA uni-variada, $P<0,05$ ). 
Alguns autores sugerem que a diminuição do número de glomérulos por campo apresenta relação inversamente proporcional ao tamanho dos mesmos, uma vez que o menor número de glomérulos levaria à hipertrofia dos glomérulos remanescentes. Nesse caso, tal processo de hipertrofia glomerular é mediado pelo fator de crescimento vascular endotelial. ${ }^{19,20}$ No entanto, este fato não foi demonstrado no presente estudo, uma vez que o grupo de menor densidade volumétrica glomerular (HP2) não mostrou aumento do tamanho dos glomérulos remanescentes. Em vez disso, o grupo HP1 mostrou menor diâmetro glomerular quando comparado ao C1.

Possivelmente, uma menor Vv reduziria a superfície de filtração renal e diminuiria a habilidade dos rins de excretar sódio, podendo levar a alterações pressóricas..$^{19}$ Dessa forma, alterações morfológicas dessa natureza podem trazer sérias implicações na saúde, predispondo o indivíduo a doenças renais e hipertensão. ${ }^{19,20}$

Este fato foi observado no grupo de HP1, que apresentou aumento na pressão arterial sistólica, provavelmente relacionada com a redução da densidade volumétrica glomerular e o diâmetro do glomérulo. Assim, a pressão sanguínea sistólica é aumentada provavelmente devido a uma disfunção renal. No entanto, a pressão sanguínea sistólica elevada no grupo HP2 pode ser explicada pela menor densidade volumétrica glomerular e maiores níveis de aldosterona no sangue.

Em relação aos padrões bioquímicos, o aumento sérico de ureia é um achado comum na literatura quando animais ou humanos são submetidos à "dieta da proteína”. 3,12,19-21

Em casos de desnutrição e/ou aumento do catabolismo, a síntese hepática de albumina pode ser reduzida, o que explica o fato de os grupos HP e C2 apresentarem as concentrações de albumina inferiores aos do grupo controle. Em relação à proteína total, o grupo HP2 apresentou as menores concentrações plasmáticas, o que mostra que a combinação de três fatores - restrição alimentar, alterações no substrato energético e diminuição da produção de albumina hepática - tem um efeito sinérgico sobre estes marcadores (tabela 3). ${ }^{22-24}$

Segundo alguns autores, dietas hiperlipídicas também estão associadas com o aumento da produção de espécies reativas de oxigênio, com consequente aumento do estresse oxidativo e ativação de um fator nuclear pró-inflamatório de transcrição chamado de NF-k $\beta$, responsável pela transcrição de proteínas pró-inflamatórias, tais como a interleucina-6..$^{21,25}$ Dietas ricas em gorduras saturadas, como a "dieta da proteína", promove a síntese de eicosanoides pró-inflamatórios (prostaglandinas e tromboxano série 2 e $4 .{ }^{21,25,26}$ No presente estudo, os animais alimentados com "dieta da proteína" tiveram as maiores concentrações de interleucina-6, corroborando outros estudos, que mostraram que essas dietas estimulam a geração de um ambiente pró-inflamatório, aumentando a probabilidade de desenvolver doenças crônicas. ${ }^{26,27}$ 


\section{Conclusão}

O consumo da dieta da "proteína” pode causar aumento da pressão arterial sistólica, morfologia renal anormal, diâmetro e densidade volumétrica glomerular reduzidos, e aumento da produção de interleucina-6, um marcador inflamatório importante. Assim, este estudo sugere que a "dieta da proteína" leva a alterações no tecido renal, predispondo o indivíduo ao desenvolvimento de doenças crônicas.

São necessários outros estudos com metodologia semelhante e maior tempo de avaliação, a fim de verificar se outras alterações podem acontecer ou mesmo se podem ocorrer adaptações nos parâmetros estudados.

\section{Agradecimentos}

Os autores agradecem ao Projeto Reestruturação e Expansão das Faculdades Federais (REUNI), à Pró-Reitoria de Pesquisa, Pós-Graduação e Inovação da Universidade Federal Fluminense (PROPPI - UFF) e à Fundação de Pesquisa do Estado do Rio de Janeiro (FAPERJ), pelo apoio concedido à iniciação científica e ao Programa em Ciências Aplicadas de Produtos de Saúde da Universidade Federal Fluminense.

\section{Referências}

1. Truby H, Hiscutt R, Herriot A, Stanley M, Looy A, Kenneth R. et al. Commercial weight loss diets meet nutrient requirements in free living adults over 8 weeks: a randomized controlled weight loss trial. Nutrition Journal 2008; 7:(25):1-13.

2. Jallinoja P, Niva M, Helakorpi S, Kahma N. Food choices, perceptions of healthiness, and eating motives of self-identified followers of a low-carbohydrate diet. Food \& Nutrition Research. 2014; 58:(10):1-9.

3. Atkins RC. Atkins new diet revolution. $2^{a}$ ed. New York: Harper Collins Publishers; 1999. 560 p.

4. Aparicio VA, Nebot E, Heredia JM, Aranda P. Efectos metabólicos, renales yóseos delas dietas hiperproteicas. Papel regulador del ejercicio. Revista Andaluza de Medicina del Deporte 2010; 03(4):153-158.

5. Martin FW, Armonstrong LE, Rodriguez NR. Dietary protein intake and renal function. Nutrition \& Metabolism 2005; 2(25):1-9.

6. Tirosh A, Golan R, Harman-Boehm I, Henkin Y, Schwarzfuchs D, Rudich A, et al. Renal function following three distinct weight loss dietary strategies during 2 years of a randomized controlled trial. Diabetes Care 2013; 36(8):2225-2232. 
7. Escribano J, Luque V, Ferre N, Zaragoza-Jordana M, Grote V, Koletzko B. et al.; Increased protein intake augments kidney volume and function in healthy infants. Kidney International 2011; 79(1):783-790.

8. Frank H, Graf J, Amann-Gassner U, Bratke R, Daniel H, Heemann U, et al. Effect of short-term high-protein compared with normal-protein diets on renal hemodynamics and associated variables in healthy young men. American Journal of Clinical Nutrition 2009; 90:1059-1600.

9. Shevalye H, Lupachyk S, Watcho P, Stavniichuck R, Kazim K, Abboud E, et al. Prediabetic nephropathy as an early consequence of the high-calorie/high-fat diet: relation to oxidative stress. Endocrinology 2012; 153(3):1152-1161.

10. Ruggiero C, Ehrenshaft E, Stadler K., High-fat diet induces an initial adaptation of mitochondrial bioenergetics in the kidney despite evident oxidative stress and mitochondrial ROS production. American Journal of Physiology, Endocrinology and Metabolism 2011; 300(6):1047-1058.

11. Juraschek SP, Appel LJ, Anderson CAM, Miller ER. Effect of a high-protein diet on kidney function in healthy adults: results from the omni heart trial. American journal of kidney diseases: the Official Journal of the National Kidney Foundation 2013; 61(4):547-554.

12. Aguila MB, Pinheiro AR, Aquino JC, Gomes AP, Mandarim-de-Lacerda CA. Different edible oil beneficial effects (canola oil, fish oil, palm oil, olive oil, and soybean oil) on spontaneously hypertensive rat glomerular enlargement and glomeruli number. Prostaglandins Other Lipid Mediators 2005; 76(1-4):74-85.

13. Naude CE, Schoonees A, Senekal M, Young T, Garner P, Volmink J. Low carbohydrate versus isoenergetic balanced diets for reducing weight and cardiovascular risk: a systematic review and meta-analysis. PLoS ONE 2014; 9(7):1-30.

14. Souza RJ, Bray GA, Carey VJ, Salão KD, LeBoff MS, Loria CM, et al. Effects of 4 weight-loss diets differing in fat, protein, and carbohydrate on fat mass, lean mass, visceral adipose tissue, and hepatic fat: results from the POUNDS LOST trial. The American Journal of Clinical Nutrition 2012; 95(3):614-625.

15. Inuzuka-Nakaharada LMI. Dieta cetogênica e dieta de Atkins modificada no tratamento da epilepsia refratária em crianças e adultos. Journal of Epilepsy and Clinical Neurophysiology 2008; 14(2):65-69.

16. Pérez-Guisado J, Muñoz-Serrano A, Alonso-Moraga A. Spanish ketogenic mediterranean diet: a healthy cardiovascular diet for weight loss. Nutrition Journal 2008; 30(7):1-7.

17. Escribano J, Luque V, Ferre N, Zaragoza-Jordana M, Grote V, Koletzko B, et al. Increased protein intake augments kidney volume and function in healthy infants. Kidney International 2011; 79:783-790.

18. Souza DB, Silva D, Marinho Costa Silva C, Barcelos F, Silva Costa W, Martins Cortes C. Effects of immobilization stress on kidneys of wistar male rats: a morphometrical and stereological analysis. Kidney Blood Pressure Research 2011; 34(6):424-429.

19. Hoy WE, Bertram JF, Denton RD, Zimany RM, Samuel T, Hughson MD. Nephron number, glomerular volume, renal disease and hypertension. Current Opinion in Nephrology and Hypertension 2008; 17(3):258-265. 
20. Juraschek SP, Appel LJ, Anderson CAM, Miller ER. Effect of a high-protein diet on kidney function in healthy adults: results from the omniheart trial. American Journal of Kidney Disease 2013; 61(4):547-54.

21. Li L, Zhao Z, Xia J, Xin L, Chen Y, Yang S, Li K. A long-term high-fat/high-sucrose diet promotes kidney lipid deposition and causes apoptosis and glomerular hypertrophy in bama minipigs. PLoS One 2015; 10(11):1-16.

22. Schwingshackl L, Hoffman G. Comparison of high vs. normal/low protein diets on renal function in subjects without chronic kidney disease: a systematic review and meta-analysis. PLoS One 2014; 9(5):1-13.

23. Waitzberg DL. Nutrição oral, enteral e parenteral na prática clínica. 4 ed. São Paulo: Atheneu; 2009. $3200 \mathrm{p}$.

24. Guyton AC, Hall JE. Tratado de fisiologia médica. 11ª ed. Rio de Janeiro: Elsevier; 2006. 1152 p.

25. Lee D, Jackson K, Knowlton N, Wages J, Alaupovic P, Samuelsson A, et al. Oxidative stress and inflammation in renal patients and healthy subjects. PLoS One 2011; 6(7):1-10.

26. Lottenberg AMP. Importância da gordura alimentar na prevenção e no controle de distúrbios metabólicos e da doença cardiovascular. Arquivos Brasileiros de Endocrinologia e Metabologia 2009; 53(5):1-13.

27. Genaro OS, Sarkis KS, Martini LA. O efeito da restrição calórica na longevidade. Arquivos Brasileiros de Endocrinologia e Metabologia 2009; 53(5):1-6.

Recebido: 28/8/2015

Revisado: 18/11/2015

Aceito: 28/5/2016 
